\title{
Health and health care of rural populations in the UK: is it better or worse?
}

\author{
Ian S Watt, Antony J Franks, Trevor A Sheldon
}

\begin{abstract}
Objective - To review available evidence on the problems facing rural health care in the UK. In particular, to determine whether the health of rural populations is worse than that of town dwellers and how the quality of health care is influenced by rurality.

Criteria for inclusion and exclusion of articles - A wide variety of publications and data sources were used. A number of computerised databases with different specialisations (for example medical, health care management) were used to identify relevant published articles. In addition, reports, reviews, and surveys produced by agencies for local circulation were identified by approaching academic, service, and voluntary bodies thought likely to have an interest in rural health. Although this "grey" literature is not subject to peer review, the relative lack of relevant $U K$ publications made it a useful data source for illustrative purposes. Similarly, published articles based on rural health in other developed countries were used when UK data were lacking.
\end{abstract}

Conclusions - Although the evidence concerning the health and health care of the UK rural populations is suggestive, it is very general and further research is needed. Levels of urban health seem to be generally worse than in rural areas, but contradictions do exist. The evidence on quality of care suggests that service accessibility is a central problem, and rural populations have poorer access than others. Within rural populations, such disadvantage is not uniformly experienced - it affects some groups more than others. In addition, the NHS does not seem to have a consistent policy about whether rurality should influence resource allocation, and how it should be incorporated.

\section{( $\mathcal{F}$ Epidemiol Community Health 1994;48:16-21)}

While the health and health care of rural populations are seen as specific concerns in many other developed and developing countries, ${ }^{1}$ concern in Britain has focused mainly on the problems of towns. ${ }^{2}$
One of the ideals on which the National Health Service was founded is that of providing a uniform standard of care for all - to ensure, as Bevan said in 1945, "that an equally good service is available everywhere". ${ }^{3}$ There is evidence, however, that this ideal has not been met, notably summarised by Tudor Hart's "inverse care law". ${ }^{4}$ In contrast with other countries, most of the debate over variations in service in Britain has ignored rura areas. There are several possible explanations. Firstly, the rural population of the UK is smaller, less economically important, and the distances involved are less than in other developed countries such as Canada, Australia, and the USA. Secondly, there is a belief that rural areas do not suffer from those social problems seen in the city and that their population is relatively healthy. Thirdly, has been a belief that the quality of NHS care prevents the problems associated with rurality seen in other developed countries. ${ }^{56}$

These assumptions, though generally held, are worth investigating, because if they are incorrect, rural health care should receive higher priority from Britain's health service. This report aims to investigate them by using the available evidence to answer three main questions:

What is meant by rural?

Is the health of rural populations worse than that of urban communities?

How may the quality of health care be influenced by rurality?

\section{What is meant by rural?}

Rural areas are commonly defined by their low density of population. ${ }^{78}$ For example, one OPCS definition defines as rural those persons living in settlements of up to 1000 persons. $^{9}$ While population density has the advantage of simplicity, used in isolation its specificity can be criticised since some inner city areas have low resident populations. More complex measures have combined different elements of rurality (for example, population density, numbers employed in agriculture) into a single index. ${ }^{1011}$ These approaches probably have greater validity in identifying rurality than single component definitions, but they are relatively complex to calculate and, depending on the variables used in the index, need to be updated regularly to maintain their accuracy. 
Moscovice has argued ${ }^{8}$ that because of the multidimensional nature of the concept of rurality, a single, agreed-upon measure may be difficult to achieve and, indeed, many authors who write on rural health and health care are pragmatic in their approach and define as rural all those areas which are physically not urban or suburban.

\section{Is the health of rural populations worse than that of urban communities?}

Part of the difficulty in answering this question is the lack of a standard definition of rurality. The definition used will determine the pattern of separation of rural from urban in any study of health or health care. In general, more detailed and complex definitions will increase the likelihood that any differences will be detected but will be more difficult to work with.

\section{MORTALITY}

As early as the mid 19th century it had been shown that urban areas had higher mortality, ${ }^{12}$ a difference which has continued in more recent reviews. ${ }^{13-15}$ This masks more subtle variations, however. In the UK, some rural northern districts have higher mortality than urban districts in the south, ${ }^{16}$ and Bentham, ${ }^{17}$ using standardised mortality ratios (SMRs) and Cloke's index of rurality, ${ }^{11}$ showed a persistent tendency for mortality to be higher in the more "truly" rural areas than the more "urbanised" rural areas.

\section{MORBIDITY}

Most morbidity information does not permit urban/rural analysis, although some information can be gained from the national morbidity studies undertaken by samples of general practitioners. Recent studies have found patients living in a rural area to be much less likely overall to consult a GP than their urban counterparts, ${ }^{1819}$ particularly for conditions classified as trivial or intermediate. ${ }^{19}$ These findings are open to varying interpretations and do not necessarily reflect greater ill health in urban than rural areas. They may, for example, represent different patterns of illness behaviour, differing accessibility of primary care, or variations of practitioner behaviour rather than true variations in health.

In a national health and lifestyle survey, Blaxter found the health of people living in areas classified as "resort (ie seaside tourist area)/rural" was generally better than average for each of the health dimensions measured, ${ }^{20}$ but pointed out that the overall figures may hide finer details. Balarajan, using data from the General Household Survey (GHS), found an odds ratio of 1.06 (95\% confidence interval (CI) $1.03,1.09$ ) for self-reported chronic illness in metropolitan compared with nonmetropolitan areas. ${ }^{21}$ This broad urban/rural analysis is in contrast with a study in East
Anglia, which used questions on self perceived acute and chronic illness similar to those in the GHS, and found higher proportions of both short term and limiting long-standing illness in parishes far (15-21 miles) from Norwich compared with those nearer to and within the city itself. ${ }^{22}$

Data from a large study of health and deprivation in the northern region of England were recently reanalysed to allow rural-urban contrasts to be made. ${ }^{23}$ The health indicators used were the SMR for all deaths under 65 years of age, the percentage of people unfit for work, and the percentage of babies born weighing less than $2800 \mathrm{~g}$. Comparison between matched rural and urban wards at the extremes of the socioeconomic spectrum showed similar health patterns. However, when the remoter parts of the region and wards in conurbations were compared, the rural areas were shown to have better health than the urban areas. These findings are at variance with Bentham's mortality based study. ${ }^{17}$

In terms of mental health, difficulties in distinguishing the effects of differences in case identification by $\mathrm{GPs}^{24}$ preparedness by patients to admit to symptoms of psychiatric illness, ${ }^{25-28}$ and attitudes to mental illness among the general public ${ }^{28}$ make it difficult to interpret any apparent urban-rural differences in psychiatric morbidity such as those suggested by differences in tranquilliser prescribing..$^{29}$ Indeed one researcher has stated that the evidence needed to make definitive statements about urban and rural rates of psychiatric disorders is not available. ${ }^{30}$

\section{SOCIAL CONDITIONS}

Health care needs are affected by social conditions, ${ }^{3132}$ though the deprivation indices in common use have been criticised in that they may be better able to reflect and identify urban than rural deprivation. ${ }^{323}$ Deprivation measures suffer from potential difficulties over their validity in different settings. Car ownership, a frequent component of deprivation indices, is of different significance in town (where its lack may be a measure of poverty) and country (where it may be viewed as an essential of life maintained even in the face of poverty). The use of wards, which are larger in rural districts, will tend to mask pockets of deprivation due to the presence of scattered, small and heterogeneous populations; this weakness can partially be overcome by the use of enumeration districts to aggregate measures of deprivation. ${ }^{34}$

Notwithstanding the above comments, there is growing evidence that deprivation of a comparable degree to that in the cities can be found in rural areas. ${ }^{35}$ Immigration of elderly retired people and emigration of young people seeking employment threaten social cohesion. ${ }^{2}$ Rural agricultural employment declined by $12 \%$ between 1978 and 1988 and a further decline of 10 to $15 \%$ is forecast for the $1990 \mathrm{~s}^{36}$ Homelessness is reported to be growing faster in rural areas than in towns, ${ }^{37}$ and the standard of the housing stock is worse. ${ }^{38} 39$ 
How the quality of health care may be influenced by rurality

Of the six dimensions of health care quality identified by Maxwell $1^{40}$ (access, relevance, effectiveness, equity, social acceptability, and efficiency) access may be the one most influenced by rurality, as service provision becomes increasingly centralised. Although evidence is scant, barriers to access may have important effects on health outcomes. A recent study of the presentation of colorectal cancer in France showed that a lower proportion of rural than urban populations was treated in specialised health centres, and a higher percentage was diagnosed at a later stage, especially in women. ${ }^{41}$

ACCESS TO PRIMARY CARE

There is evidence that distance from a general practice surgery is negatively related to consultation rates ${ }^{2242-44}$ - so called "distance decay". In their East Anglia based study, ${ }^{22}$ Haynes and Bentham showed that this existed even for people with long-standing (self reported) illness.

Variation in consultation rate in relation to distance from the surgery is hard to interpret. While it may indicate some hindrance to access, the effects of distance may also be explained, for example, by variations in morbidity (although this was not the case in Haynes and Bentham's study ${ }^{22}$ ). It is also possible that frequent users may have chosen to live near GP surgeries. What is not clear from the studies is the degree to which decreased use of primary care with increasing distance represents unmet need. Studies failed to show that home visiting rates were increased in rural areas to compensate for low consultation rates. ${ }^{45} 46$

Access to general practice may be improved by provision of branch surgeries. ${ }^{47}$ Although these have been shown to be particularly beneficial to those with a high likely demand, such as the elderly, ${ }^{48}$ they may be unpopular with GPs because of the poor facilities ${ }^{49}$ and there has been a recent tendency for such provision to be closed ${ }^{47}$ No evidence exists on the relative impact on outcome of a poor quality of facility as opposed to improved access.

Another way in which access difficulties have traditionally been overcome is through mobile service provision. For example, the average distance travelled by those using a mobile mother and baby clinic in Wales was between $\frac{1}{4}$ and $\frac{1}{2}$ mile, whereas without it $73 \%$ would have had to travel more than 5 miles to their GP. ${ }^{50}$ While mobile provision may improve access and therefore equity for rural populations, it is staff intensive and often seen as less efficient than static provision, leading to a debate on the relative weights to be given to the different dimensions of quality in providing health care.

\section{ACCESS TO HOSPITALS}

"Distance decay" has been shown to occur for hospital as well as GP consultations. ${ }^{51-53}$ Evid- ence from the USA suggests that it may even occur for more specialised facilities such as cancer hospitals. ${ }^{54}$ The frequency of hospital visits has also been shown to decrease the further a patient lives from the hospital. ${ }^{55-57}$ Gruer has shown that lower referral rates to hospital are related to increased distance of residence, both from the GP and the hospital. ${ }^{58}$ She also found that the number of patients either admitted to hospital, or put on a waiting list for admission, was significantly higher in those living more than 40 miles from Edinburgh than in those living closer. This was interpreted as showing that those living further away were more severely ill when referred. However, it is possible that they are being referred at a more appropriate time compared with patients who live nearer, or that perceptions held by hospital doctors about the difficulties faced by patients on return journeys influence their decisions. The relevance of these findings to the debate on rural health is unclear but the findings could be confounded by distance from a hospital.

Most outpatient referrals in the UK are filtered through a GP first, thus such variations for outpatient attendances may simply be a reflection of the geographical variations in GP consultations. More research is needed to determine whether hospital outpatient attendances and inpatient admissions show additional variation related to geography. Haynes and Bentham ${ }^{22}$ have suggested that any such additional variation may depend on the type of illness. Their study showed that low rates of outpatient attendance for people with longstanding illness are largely the result of low rates of GP consultation, but that rural areas provide a higher rate for inpatient hospital admissions than urban ones. For people with more acute illness, the study showed lower utilisation rates in remote than accessible rural areas; the difference was slightly increased at both outpatient and inpatient stage.

Norway has a system of health care that has concentrated on equity and the removal of financial barriers to use. A recent retrospective cohort study, however, showed that rurality was associated with a decreased referral rate per GP visit after adjusting for health and social factors, which indicates a degree of inequity in access to referral services. ${ }^{59}$

A study in rural Australia ${ }^{60}$ suggested that since the number of patients who referred themselves to hospital fell away more quickly than the number of GP referred patients, GPs may have a mitigating effect against distance by providing an additional impetus for patients who might otherwise be reluctant to travel. However, this finding might alternatively have been the result of more distant GPs providing a wider range of care than those nearer the hospital. A greater understanding of the role of distance in the use of hospital services requires longitudinal studies which follow people from the decision to consult the GP through to hospital outpatient attendance and admission and additional related data to allow categorisation of patients as rural or urban. 
COMMUNITY HOSPITALS VERSUS DISTRICT

GENERAL HOSPITALS

Since the 1960s district general hospitals have been the main source of British hospital care ${ }^{6162}$ a policy which has seen hospital services become increasingly centralised and urban based. The policy has not been without its critics, ${ }^{63}$ especially in rural areas ${ }^{64}$ where these services were traditionally provided by locally accessible hospitals, often referred to as GP or cottage hospitals but now commonly called community hospitals.

Community hospitals may increase access to care and since the 1970s have been viewed more favourably by policy makers ${ }^{6566}$ with a consequent slow down in their rate of closure. However, Fearn ${ }^{2}$ argues that community hospitals still fit uneasily into the hospital system and are vulnerable in a recession.

The arguments against the provision of community hospitals have centred on their lack of specialised facilities and the perceived economies of scale offered by district general hospitals. ${ }^{52}$ This ignores the fact that highly specialised services are not required for many hospital inpatients and outpatients. The argument for economies of scale is partial; if overal social costs and not just costs to the NHS are considered, decentralised outpatient services, for example, have been shown to be costeffective. ${ }^{526768}$ In addition, it should be recognised that the provision of local clinics can increase attendances when compared to a centralised service. ${ }^{5268}$ The assertion that district general hospitals are cheaper than community hospitals for inpatient care may be simplistic. Some researchers have found the opposite,${ }^{6469}$ at least in terms of costs per inpatient day and per inpatient case, although no account is taken of the nature and severity of the illness and the quality of care.

The personal costs of accessing centralised services are not equally distributed within rural communities. Transport to hospital in a rural area is particularly difficult for individuals who do not have access to a car, especially in the light of declining rural public transport; ${ }^{7071}$ other groups with reduced mobility such as the elderly, women with preschool children, low income groups, the disabled, and adolescents ${ }^{72-74}$ also have a greater need for health care. ${ }^{73}$ Thus a "come and get it" strategy ${ }^{75}$ whereby those who need the health service most should be expected to come first to the queue and to stay longest in it may not be equitable. Future research might usefully consider how the distance decay effect varies between social groups and health care needs.

\section{FUNDING RURAL HEAITH CARE}

To provide high quality health care for rural populations requires, as in urban areas, adequate funding. Most of the available evidence indicates that the direct costs of providing services in rural areas tend to be higher than in urban areas. ${ }^{76}$ Therefore resource allocation based on capitation can disadvantage rural areas. There are some examples where the high unit costs of providing health services in rural areas are explicitly recognised by funding agencies; for example, the funding of community health services in Wales and Scotland have a weighting for sparsity..$^{778}$

General practice is an example of service provision where recognition is given throughout the UK to the higher costs faced in rural areas, mainly by payments based on the proportion of a practice's patients living beyond a certain distance from the main surgery. ${ }^{79}$ The recent inclusion in GP payments of a deprivation supplement based on the Jarman UPA8 score, however, may put rural practices at a disadvantage since the score was initially derived for urban areas. ${ }^{80}$ Rural pharmacies, which may only have small amounts of business, are another rural health provision which receive national recognition of their high costs. ${ }^{76}$

Despite these examples, the problems of providing quality health care to rural populations are not universally recognised in resource allocation. ${ }^{81}$ Neither the Resource Allocation Working Party (RAWP) formula nor the new weighted formula which replaced RAWP takes account of rurality. ${ }^{82}$ The NHS does not seem to have a consistent policy about whether rurality should influence resource allocation, and how it could be incorporated. More research into the costs of providing health care to rural communities that is of equal quality to that provided in urban areas is needed.

\section{Conclusion}

There are two central difficulties that prevent the questions outlined in the introduction being clearly answered. The first is the lack of a widely used, consistent, and robust definition of "rural" and the second is the paucity of data collected in settings, and in sufficient detail, which would allow the confident conclusion that there were differences between urban and rural populations.

Specific questions that need to be addressed by further research include:

The practicality of collecting morbidity and utilisation data in ways that will allow routine categorisation into rural and urban;

The impact of distance among the rural poor on health service utilisation;

The effect of rurality on the outcome of common conditions for which agreed treatments exist (eg myocardial infarction, colonic cancer);

The real costs (to service, patient, and society) of different models of health care provision in rural settings.

For many people living in the countryside has many benefits, and the rural idyll is often the dream of a number of city dwellers. Problems do exist, however. These are often little different from those in urban areas, but their solution requires not just their recognition but for them to be seen as existing in a rural context. Remoteness has been defined as, "where there are problems of access which it has not been thought worthwhile to overcome,"83 emphasising that the problems of 
rural areas should be viewed not just as the result of geography, but also as a result of social, historical, and political factors.

We would like to thank Dr J Wilkinson for providing the initial impetus for this review.

1 Roemer MI. Rural health care: a worldwide issue. Bull Pan Am Health Organ 1987;21:326-33.

2 Fearn R. Rural health care: a British success or a tale of unmet need? Soc Sci Med 1987;24(3):263-74.

3 Bevan A. Memorandum by the Minister of Health to the Cabinet, 5 October 1945. London: Public Record Office. CAB 129/3.

4 Hart JT. The inverse care law. Lancet 1971;i:405-12.

5 Carmody J. Rural health services research 1968-90. Mary land: US Department of Health and Human Services, 1991.

6 Hospitals and Health Services Commission. Rural health in Australia. Canberra: Parliamentary Paper No 206/1976, 1976.

7 Mason S, Taylor R. Tackling deprivation in rural areas. Cirencester: ACRE, 1990

8 Moscovice IS. Rural hospitals: a literature synthesis and health services research agenda. Health Serv Res 1989;23(6):891-930.

9 Rural Development Commission. The changing population of rural England. London: RDC, 1989. Rural research note no 2 .

10 Countryside Review Committee. Rural communities: a discussion paper. London: HMSO, 1977. Topic Paper No 1.

11 Cloke PJ. An index of rurality for England and Wales. Regional Studies 1977;11:31-46.

12 Registrar General. Supplement to the 25th annual report of the Registrar General. London: HMSO, 1864

13 Registrar General. The Registrar General's decennial supple ment. England and Wales 1961. Area mortality. London: MMSO, 1967.

14 Office of Population Censuses and Surveys. Area mortality: decennial supplement 1969-73, England and Wales. Lon don: HMSO, 1981

15 Office of Population Censuses and Surveys. Mortality and geography. A review in the mid 1980s England and Wales. London: HMSO, 1989.

16 Chilvers C. Regional mortality 1969-73. Population Trends 1978;11:16-20.

17 Bentham GG. Mortality in the more rural areas of England and Wales. Area 1984;16(3):219-26.

18 Office of Population Censuses and Surveys. Morbidity statistics from general practice. Second national study 1970-71. istics from general practice.

19 Office of Population Censuses and Surveys. Morbidity statistics from general practice. Third national study 1981-82. istics from general practice.

20 Blaxter M. Health and lifestyles. London: Tavistock/Routledge, 1990.

21 Balarajan R, Yuen P, Machin D. Socio-economic differentials in health status: their application in health care planning and resource allocation. Surrey: Epidemiology and Public Health Research Unit, University of Surrey, 1987.

22 Haynes $R$, Bentham $G$. The effects of accessibility on GP consultations; out patient attendances and in patient admissions in Norfolk, England. Soc Sci Med 1982;16:5619.

23 Phillimore P, Reading R. A rural disadvantage? Urbanrural health differences in

24 Zintl-Wiegand A, Krumm B, Weyerer S, Dilling H. Psychiatric morbidity and referral rates in general practice: comparison of an industrial town and a rural area in West Germany. Social Psychiatry Psychiatr Epidemiol Germany. Socia

25 Gift TE, Zastowny TR. Psychiatric service utilisation differences by sex and locale. Int $\mathcal{f}$ Soc Psychiatry 1990;36(1):11-17.

26 D'Arcy C, Brockman J. Changing public recognition of psychiatric symptoms and Blackfoot revisited. $\mathcal{F}$ Health Soc Behav 1976;17:302-10.

27 Laine A, Lehtinen V. Attitudes towards mental illness and their relationship to social structure and mental hospital bed utilisation in two Finnish rural communities. Social Psychiatry 1973;8:117-23.

28 Keatinge C. Community factors influencing psychiatric hospital utilization in rural and urban Ireland. Community Ment Health $\mathcal{F}$ 1987;23(3):192-203.

29 Williams P, Gabe J. Urban-rural differences in tranquillise prescribing: a critique of the minimalist posit

30 Kenkel MB. Stress-coping-support in rural communities: model for primary prevention. Am f Community Psychol 1986;14(5):457-78

31 Carstairs V. Multiple deprivation and health state. Community Medicine 1981;3:4-13.

32 Townsend $\mathrm{P}$, Phillmore $\mathrm{P}$, Beattie A. Health and deprivation: inequality in the north. London: Croom Helm, 1979.

33 Knox P. Disadvantaged households and areas of deprivation: microdata for the 1981 census of Scotland. Environment and Planning 1985;17:413-15.

34 Reading RF, Openshaw S, Jarvis SN. Measuring child health inequalities using aggregations of enumeration districts f Public Health Med 1990;12(3/4):160-7.

35 Townsend P. Poverty in the UK. Harmondsworth: Penguin, 1979 .
36 When shepherds give up their flocks. The Guardian 1992. January 7

37 Lambert C, Jeffers S, Burton P, Bramley G. Homelessness in rural areas. Salisbury: Rural Development Commission, 1992. Rural research series no 12 .

38 McLauglin B. Country crisis. London: Media Services Unit, National Extension College Channel 4, ATV, 1983. Quoted in Abbot P, Payne G, eds. New directions in the sociology of health. London: The Falmer Press, 1990.

39 Larkin A. Housing and the poor. In Walker A, ed. Rural poverty. London: CPAG, 1978.

40 Maxwell RJ. Quality assessment in health. BMf 1984;288:1470-2.

41 Launoy G, Le Coutour X, Gignoux M, Pottier D, Dugleux $\mathrm{G}$. Influence of rural environment on diagnosis, treatment and prognosis of colorectal cancer. $\mathcal{F}$ Epidemiol Community Health 1992;46:365-7.

42 Ritchie J, Jacoby A, Bone M. Access to primary health care. London: HMSO, 1981.

43 Hopkins EJ, Pye A, Solomon M, Solomon S. The relation of patients' age, sex, and distance from surgery to the demand on the family doctor. $f R$ Coll Gen Pract 1968;16:368-78.

44 Parkin D. Distance as an influence on demand in general practice. Epidemiology and Community Health 1979;33:96-9.

45 Humphreys RC. Home visiting in a rural practice. $B M \mathcal{F}$ 1981;282:115-6.

46 Wilson JB. Work load in a rural practice over the past eighteen years. Lancet 1982;i:733-4.

47 Haynes $R$. The geography of health services in Britain. London: Croom Helm, 1987 .

48 Fearn R, Haynes RM, Bentham CG. Role of branch surgeries in a rural area. $\mathcal{F} R$ Coll Gen Pract 1984;34:488-91.

$49 \mathrm{McAvoy} B R$. Trials and tribulations of closing branch surgeries. Update 1984:50-8.

50 Longley M, Pithouse A. Keep on moving. Health Services fournal 1990;100:1184-5.

51 Hobbs MST, Aceson ED. Perinatal mortality and the organisation of obstetric services in the Oxford area in 1962. BMY 1966;i:499-505.

52 Russell IT, Reid NG, Philips PR, Glass NJ, Akehurst RL. The transfer of outpatient clinics to rural hospitals: a feasibility study and cost benefit analysis. In Anderson J, ed. Medical informatics Europe 1978 - Proceedings of the 1st Congress of the European Federation for Informatics. New York: Springer-Verlag, 1978.

53 Haynes RM, Bentham CG. Accessibility and the use of hospitals in rural areas. Area 1979;11:186-91.

54 Greenberg ER, Dain B, Freeman D, Yates J, Korson R. Referral of lung cancer patients to hospital cancer centers. Cancer 1988;62:1647-52.

55 Cross KW, Turner RD. Factors affecting the visiting pattern of geriatric patients in a rural area. British fournal of tern of geriatric patients in a rural area. British

56 Wenger GC. Old people's health and experiences of the caring services: accounts from rural communities in north $W$ ales. services: accounts from rural communities in nort

57 Haynes RM, Bentham CG. Community hospitals and rural accessibility. Farnborough: Saxon House, 1979.

58 Gruer R. Outpatient services in the Scottish border counties. Edinburgh: Scottish Home and Health Department, 1972

59 Fylkesnes K, Johnsoen R, Forde OH. The Tromso Study: factors affecting patient-initiated and provider initiated use of health care services. Sociology of Health and Illness 1992;14:275-92.

60 Walmsley DJ. The influence of distance on hospital usage in rural New South Wales. Australian fournal of Social Issues 1978;13(1):72-81.

61 Ministry of Health. A Hospital Plan for England and Wales. London: HMSO, 1962. Cmnd 1604.

62 Central Hospital Services Council. The functions of district general hospital. (Bonham Carter Report) London: general hospital.

63 Draper P. Why not plan for locally based out-patient services? Health and Social Services fournal 1986;96:1089.

64 Llewelyn Jones H. Do district general hospitals meet rural needs?: a study of the community hospital experience. Leeds: Nuffield Centre for Health Services Studies, University of Leeds, 1987. (MA dissertation.)

65 DHSS. Community hospitals - their role and development in the National Health Service. London: Department of Health and Social Security, 1974. HSC(IS)75.

66 DHSS. The future pattern of hospital provision in England. London: Department of Health and Social Security, 1980.

67 Gruer R. Economics of out-patient care. Lancet 1971;i:390

68 Goldacre MJ, Gatherer A. Peripheral out-patient clinics: use, costs, and benefits. British fournal of Preventive and Social Medicine 1977;31:205-8.

69 Treasure RAR, Davies JAJ. Contribution of a general practitioner hospital: a further study. BMf 1990;300:644 6.

70 Department of Transport. National travel survey 1978/9 report. London: HMSO, 1983.

71 Trent Regional Health Authority. Grasping the nettle: working party on health care to rural populations. Nottingham: ing party on health care to rural populations

72 Mosely MJ. Accessibility: the rural challenge. London: Methuen, 1979.

73 Bentham CG, Haynes R. A raw deal in remoter areas? Family Practitioner Services 1986;13(5):84-7. 
74 Reid N, Todd C. Travel to hospital: accessibility of outpatient services in rural communities. Health Services Management 1989;85(3):129-33.

75 Gibson DM, Goodin RE, LeGrand J. Come and get it: distributional biases in social service delivery systems. Policy and Politics 1985;13(2):109-25.

76 Woollett $S$. Counting the rural cost: the case for a rural premium. London: National Council for Voluntary Orga-

77 Welsh Office, NHS Directorate. Results of revenue formula assessment for 1990/91. Cardiff: Welsh Office, 1989.

78 Scottish Home and Health Department. Scottish health authorities revenue equalisation - report of the working party on revenue resource allocation. Edinburgh: Scottish Office, 1977

79 Department of Health. National Health Service. Statement of fees and allowances payable to general medical practitioners in England and Wales from April 1990. London: Department of Health, 1990.

80 Jarman B. Identification of under-privileged areas. $B M \mathcal{F}$ 1983;286:1705-9.

81 Mays N, Bevan G. Resource allocation in the health service. Occasional Papers on Social Administration 81. London: Bedford Square Press/NCVO, 1987.

82 Department of Health. Funding and contracts for hospital services: working paper 2. Working for Patients. London: HMSO, 1989.

83 Bloor $\mathrm{M}$, Horobin $\mathrm{G}$, Taylor $\mathrm{R}$, Williams $\mathrm{R}$. Island health care: access to primary services in the Western Isles. Occasional Paper No 3. Aberdeen: Institute of Medical Sociology, University of Aberdeen, 1978. 